\title{
Thrombolysis for Severe Intestinal Ischemia due to Midgut Volvulus in a Neonate
}

\author{
Nouredin Messaoudi ${ }^{1} \quad$ Koen Vanlede ${ }^{2}$ Dirk Vervloessem ${ }^{3} \quad$ Marc Huyghe $^{1} \quad$ Paul Leyman $^{1}$
}

${ }^{1}$ Department of General, Digestive and Pediatric Surgery, SintAugustinus Hospital, Wilrijk, Belgium

2 Department of Pediatrics, Sint-Augustinus Hospital, Wilrijk, Belgium

${ }^{3}$ Department of Pediatric Surgery, ZNA Queen Paola Children's Hospital, Antwerp, Belgium

\author{
Address for correspondence Paul Leyman, MD, Department of \\ General, Digestive and Pediatric Surgery, Sint-Augustinus Hospital, 24 \\ Oosterveldlaan, Wilrijk, Antwerp 2610, Belgium \\ (e-mail: paul.leyman@gza.be).
}

Eur J Pediatr Surg Rep 2015;3:74-77.
Abstract
Keywords
- thrombolysis
- intestinal ischemia
- malrotation

Intestinal malrotation complicated by the development of midgut volvulus presents a difficult management dilemma because of the risk of short bowel syndrome. Here, we present our experience with a case of severe intestinal ischemia after derotation in a newborn successfully managed using systemic tissue plasminogen activator. The present report supports the usefulness of thrombolysis as a therapeutic option for reperfusion of ischemic small bowel due to midgut volvulus in neonates.

\section{New Insights and the Importance for the Pediatric Surgeon}

This report supports the usefulness of thrombolysis as a therapeutic option for reperfusion of ischemic small bowel due to midgut volvulus in neonates. The authors present a case of severe intestinal ischemia after derotation in a newborn successfully managed using systemic tissue plasminogen activator.

\section{Introduction}

Neonates with intestinal malrotation are at risk for developing a midgut volvulus. This condition is a surgical emergency since significant morbidity is associated with extensive resection of ischemic bowel and subsequent short bowel syndrome. Complications depend on the length and site of the resected small intestine. Long-term total parenteral nutrition, intestinal failure-associated liver disease, catheter-associated bloodstream infections, and bacterial overgrowth are known consequences of insufficient small intestinal length. ${ }^{1,2}$ Therefore, an attempt has to be made to preserve as much small bowel as possible, certainly in cases with doubtful viability. This report describes the case of a newborn successfully treated with systemic infusion of tissue plasminogen activator ( $t-P A)$ for severe intestinal ischemia due to midgut volvulus.

received

March 18, 2015

accepted after revision

June 3, 2015

published online

August 17, 2015 10.1055/s-0035-1558460. ISSN 2194-7619.

\section{Case Report}

A male infant was born after 38 weeks' gestation, birth weight 2,920 g. Bilious vomiting and a distended abdomen was noticed a few hours after birth. Abdominal X-ray was performed that showed an air-filled stomach and a gasless abdomen ( - Fig. 1A). Doppler ultrasound examination revealed a whirl sign indicating the presence of intestinal malrotation (-Fig. 1B). The newborn was taken to the operating room for emergency surgery.

At laparotomy, a 360-degree midgut volvulus was found with obvious transmural necrosis of the jejunum and severe ischemia of the remaining small bowel. No improvement was seen after derotation. Moreover, no pulsations of the superior mesenteric artery were appreciated. A Ladd procedure was performed before closure, and a second look laparotomy was planned after 48 hours. Exploratory surgery 2 days after,

\footnotetext{
(c) 2016 Georg Thieme Verlag KG Stuttgart · New York
}

\section{License terms}

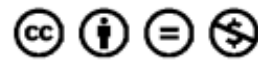


A
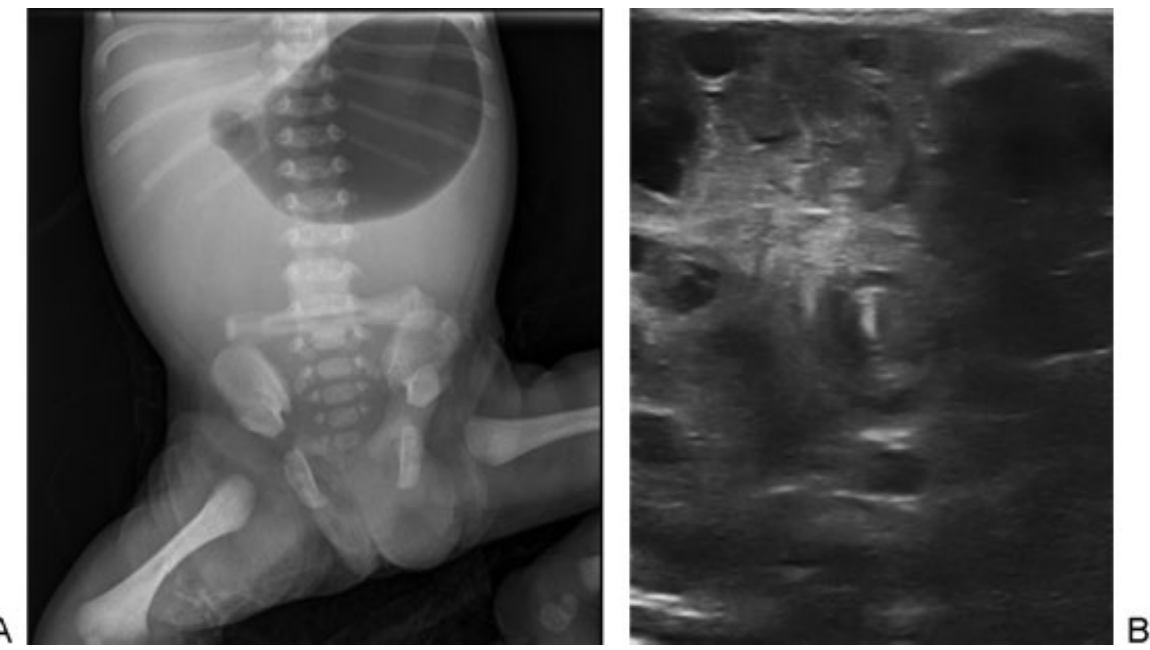

Fig. 1 (A) Abdominal X-ray demonstrating gastric air dilatation, and a gasless abdomen. (B) Ultrasound image confirming a whirl sign.

confirmed persistent necrosis of $50 \mathrm{~cm}$ jejunum, and $60 \mathrm{~cm}$ ileum with doubtful viability due to severe ischemia. Only the necrotic jejunal segment was resected, no anastomosis was performed. A clip was placed on the proximal and distal intestinal ends.

Following surgery and after parental consent, thrombolysis was initiated 24 hours after the second look laparotomy to promote clot dissolution according to a previously reported protocol. ${ }^{3}$ This consisted of a combination of t-PA at a dose of 0.25 to $0.5 \mathrm{mg} / \mathrm{kg}$ per hour for 6 hours, and fresh frozen plasma to increase plasminogen to potentiate the action of tPA. In addition, low-dose anticoagulation was provided by administering unfractionated heparin (range, $15-20 \mathrm{U} / \mathrm{kg} / \mathrm{h}$ ) for a total of 24 hours. No apparent adverse effects were noted and cranial ultrasound was normal before and after thrombolysis.

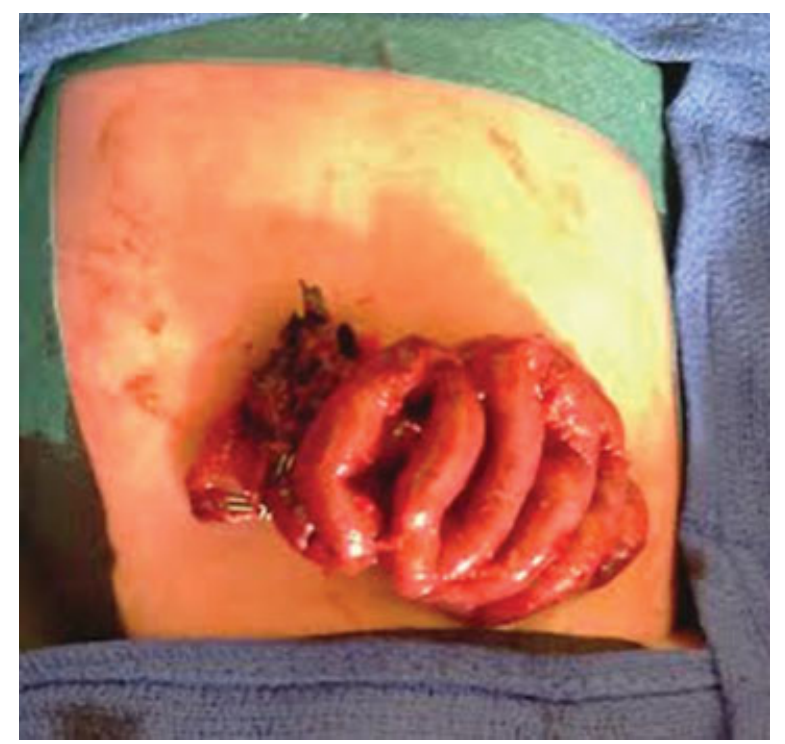

Fig. 2 Macroscopic image of the intestines after tissue plasminogen activator treatment.
Reexploration following thrombolysis and 48 hours after the second look revealed manifest reperfusion of the remaining small bowel and a pulsatile superior mesenteric artery ( - Fig. 2). No further resection was needed and an end-to-end enteral anastomosis was conducted, leaving $75 \mathrm{~cm}$ of wellvascularized small bowel.

Enteral feeding was commenced on the 15 th postoperative day and increased slowly thereafter. On postoperative day 55 , total parenteral nutrition could be weaned. At 2 months, the infant was discharged from the neonatal intensive care unit on full oral feeding. His growth and development has since been normal for his age.

\section{Discussion}

Congenital intestinal malrotation leading to midgut volvulus is a surgical emergency and operative treatment consists of derotation and a Ladd procedure to widen the base of the small bowel mesentery. ${ }^{4}$ After counterclockwise devolvulation, the viability of the small intestines is assessed for necrotic segments which warrant intestinal resection. In case of ischemic or congested bowel, a conservative approach is undertaken and a second look laparotomy is planned within 24 to 48 hours.

Supportive care is provided between the first and second surgical intervention, this focuses on aggressive fluid resuscitation, antibiotics, and parenteral nutrition. However, no attempts are made to promote the recovery of ischemic bowel. On second inspection, further bowel necrosis results in frank resection leaving the neonate at risk for a short gut and consequently long-term nutritional problems.

In 2012, a report by Kiely et al suggested the use of systemic t-PA to dissolve intravascular thrombosis in mesenteric vessels resulting in dramatic improvement of intestinal perfusion. ${ }^{3}$ Experience has been gained in the management of acute limb-threatening arterial occlusion with peripheral infusion of t-PA and the use of this thrombolytic agent in the treatment of midgut volvulus has been reported to be promising in two previous cases. ${ }^{3,5}$ Thrombolysis with t-PA 


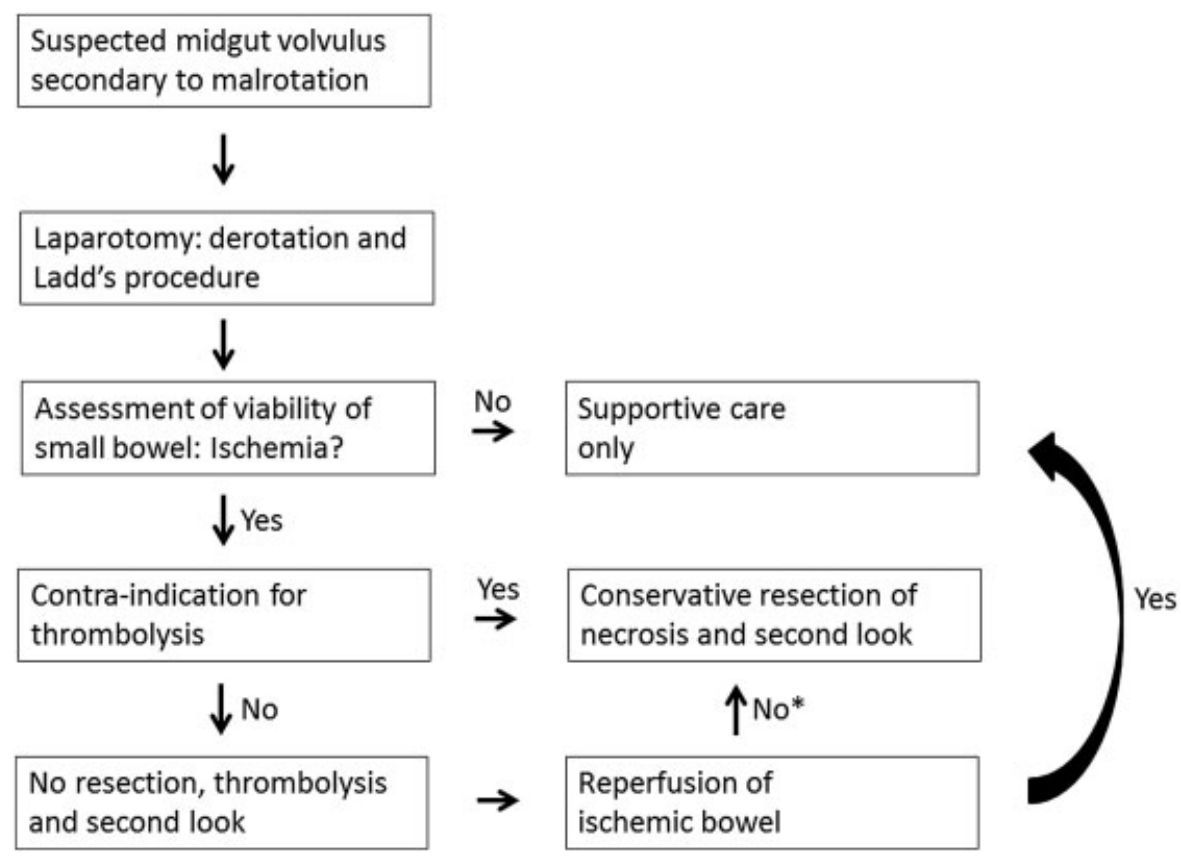

Fig. 3 Flow chart of the clinical course of midgut volvulus in neonates. ${ }^{*}$ Consider rethrombolysis after conservative resection of necrotic segments.

has also been advocated in pediatric patients for the treatment of acute ischemic stroke and venous thrombotic events (e.g., renal vein, atrial, or vena cava thrombosis). ${ }^{6-8}$

The thrombolytic activity of t-PA (alteplase) is exerted by the binding of this recombinant protein to plasminogen, generating plasmin which in turn degrades fibrin and initiates clot resorption, resulting in effective dissolution of the thrombus. ${ }^{9}$ Fibrinogen in plasma is monitored closely and cessation of infusion of t-PA is done below $1 \mathrm{~g} / \mathrm{L}$ to allow the fibrinogen level to normalize. In our case, no adverse effects have been observed, however, major complications have been documented and the potential to cause significant (gastrointestinal and intracranial) bleeding is evident. ${ }^{8,10}$

The combination of alteplase with fresh frozen plasma has a favorable effect as it preserves systemic coagulability and promotes local clot fibrinolysis by providing more plasminogen to potentiate the effect of t-PA at the thrombus site. There are several advantages of t-PA over other thrombolytic agents (such as heparin, streptokinase, and urokinase) ensuing a preference of treatment for clot dissolution in neonates and infants. These include a shorter half-life, reduced antigenicity, direct effect on plasminogen, no interference with $\alpha_{2}$-antiplasmin, more localized fibrinolytic effect and less systemic coagulopathy. ${ }^{11-13}$

In contrast to the aforementioned reports, we did not use digital massage for the mesenteric vascular tree to obtain clot disruption as described by Kiely et al. $^{3}$ In our case, the mesenteric axis was too friable to allow excessive manipulation.

The success with the use of alteplase in our patient and previous reports suggest that t-PA can be considered for the management of neonates with midgut volvulus and severe ischemia secondary to intestinal malrotation, and should be seriously considered. Our recommended course of management is illustrated in - Fig. 3. The apparent effectiveness of t-PA in treating neonatal small bowel ischemia raises the issue

Table 1 Standard contraindications of t-PA thrombolysis

\begin{tabular}{|l|}
\hline 1. Major surgery or hemorrhage within 10 days of therapy \\
\hline 2. A severe asphyxial event within 7 days of therapy \\
\hline 3. Invasive procedure within 3 days of therapy \\
\hline 4. Seizures within 48 hours of therapy \\
\hline 5. Prematurity $<32$ weeks' gestation \\
\hline 6. Systemic septicemia \\
\hline 7. Active bleeding at the time of therapy \\
\hline 8. Inability to maintain platelets $>50-100,000 / \mu \mathrm{L}$ or fibrinogen $>100 \mathrm{mg} / \mathrm{dL}$ (using transfusion support, if necessary) \\
\hline
\end{tabular}


Table 2 Clinical characteristics of neonates treated with thrombolysis

\begin{tabular}{|l|l|l|l|l|l|l|l|}
\hline Reference & Gestation & Gender & Postnatal age & $\begin{array}{l}\text { Volvulus } \\
\text { degree }\end{array}$ & $\begin{array}{l}\text { Resected } \\
\text { segment }\end{array}$ & $\begin{array}{l}\text { Adverse effects } \\
\text { of thrombolysis }\end{array}$ & $\begin{array}{l}\text { Full enteral } \\
\text { feeding }\end{array}$ \\
\hline Kiely et $\mathrm{al}^{3}$ & Term & Male & 2 d & 720 & No resection & Abdominal bleeding & $20 \mathrm{~d}$ \\
\hline Kiely et $\mathrm{al}^{3}$ & $29 \mathrm{wk}$ & Female & $6 \mathrm{~d}$ & 540 & Jejunum $10 \mathrm{~cm}$ & None & $22 \mathrm{~d}$ \\
\hline Present case & $38 \mathrm{wk}$ & Male & $1 \mathrm{~d}$ & 360 & Jejunum $50 \mathrm{~cm}$ & None & $55 \mathrm{~d}$ \\
\hline
\end{tabular}

whether thrombolysis can be used as a first-line therapy after surgical derotation, even in the presence of severely ischemic intestines. The decision to use alteplase in this context increases the risk of hemorrhage, which must be weighed against the risk of the bowel necrosis and its possible complications, certainly in premature infants. Standard contraindications of t-PA thrombolysis, as recommended by the Scientific Subcommittee on Perinatal and Pediatric Thrombosis of the Scientific and Standardization Committee of the International Society of Thrombosis and Haemostasis, ${ }^{14}$ are listed in -Table 1.

Nevertheless, our experience with thrombolysis was promising and uneventful ( - Table 2 ). Therefore, this report supports the use of this treatment modality in the management of intestinal volvulus with severe ischemia due to malrotation. Further experimental and clinical studies are warranted to corroborate this recommendation.

Conflict of Interest

None.

\section{References}

1 Goulet O, Ruemmele F. Causes and management of intestinal failure in children. Gastroenterology 2006;130(2, Suppl 1): S16-S28

2 Buchman AL. Etiology and initial management of short bowel syndrome. Gastroenterology 2006;130(2, Suppl 1):S5-S15

3 Kiely EM, Pierro A, Pierce C, Cross K, De Coppi P. Clot dissolution: a novel treatment of midgut volvulus. Pediatrics 2012;129(6): e1601-e1604
4 Burke MS, Glick PL. Gastrointestinal malrotation with volvulus in an adult. Am J Surg 2008;195(4):501-503

5 Ade-Ajayi N, Hall NJ, Liesner R, et al. Acute neonatal arterial occlusion: is thrombolysis safe and effective? J Pediatr Surg 2008;43(10):1827-1832

6 Janjua N, Nasar A, Lynch JK, Qureshi AI. Thrombolysis for ischemic stroke in children: data from the nationwide inpatient sample. Stroke 2007;38(6):1850-1854

7 Farnoux C, Camard O, Pinquier D, et al. Recombinant tissue-type plasminogen activator therapy of thrombosis in 16 neonates. J Pediatr 1998;133(1):137-140

8 Nowak-Göttl U, Schwabe D, Schneider W, Schlösser R, Kreuz W. Thrombolysis with recombinant tissue-type plasminogen activator in renal venous thrombosis in infancy. Lancet 1992;340(8827): 1105

9 Levy M, Benson LN, Burrows PE, et al. Tissue plasminogen activator for the treatment of thromboembolism in infants and children. J Pediatr 1991;118(3):467-472

10 Zenz W, Arlt F, Sodia S, Berghold A. Intracerebral hemorrhage during fibrinolytic therapy in children: a review of the literature of the last thirty years. Semin Thromb Hemost 1997;23(3): 321-332

11 Rimensberger PC, Humbert JR, Beghetti M. Management of preterm infants with intracardiac thrombi: use of thrombolytic agents. Paediatr Drugs 2001;3(12):883-898

12 Nomura F, Penny DJ, Menahem S, Pawade A, Karl TR. Surgical intervention for infective endocarditis in infancy and childhood. Ann Thorac Surg 1995;60(1):90-95

13 Nowak-Göttl U, Auberger K, Halimeh S, et al. Thrombolysis in newborns and infants. Thromb Haemost 1999;82(Suppl 1): $112-116$

14 Manco-Johnson MJ, Grabowski EF, Hellgreen M, et al. Recommendations for tPA thrombolysis in children. On behalf of the Scientific Subcommittee on Perinatal and Pediatric Thrombosis of the Scientific and Standardization Committee of the International Society of Thrombosis and Haemostasis. Thromb Haemost 2002; 88(1):157-158 